\title{
Role of Lewis Acids in Preventing the Degradation of Dithioester- Dormant Species in the RAFT Polymerization of Acrylamides in Methanol to Enable the Successful Dual Control of Molecular Weight and Tacticity
}

\begin{abstract}
Yuji Imamura and Shigeru Yamago*a
Reversible addition-fragmentation chain transfer (RAFT) polymerization of acrylamide in methanol using dithioester RAFT chain-transfer agent 2a was unsuccessful due to degradation of the end group. However, this degradation was completely suppressed by the addition of rare-earth metal triflates (RMTs). As RMTs are effective for the stereoselective polymerization of acrylamides, RAFT polymerization in the presence of RMTs afforded the corresponding poly(acrylamide)s with controlled molecular weight and tacticity. The conditions allowed the synthesis of high-molecular-weight polyacrylamides with molecular weights up to 168,000 , low dispersity $(<1.5)$ and high tacticity $(90 \%$ meso diad selectivity). The degradation mechanism initiated by nucleophilic attack of acrylamide on the dithioester group was experimentally clarified for the first time. As RMT is a Lewis acid, its coordination to the amide group of acrylamide reduces its nucleophilicity.
\end{abstract}

\section{Introduction}

Reversible addition-fragmentation chain-transfer (RAFT) polymerization is one of the most versatile reversible deactivation radical polymerization (RDRP) methods ${ }^{1}$ because of its high versatility in polymerizing various monomer families and its good functional group compatibility. However, choosing an appropriate chain-transfer agent (CTA, 1 ), particularly the $Z$ group, is necessary to achieve successful control (Figure 1 ). For example, dithioesters $\left(\mathrm{Z}=\mathrm{alkyl}\right.$ and aryl) and trithiocarbonates $\left(\mathrm{Z}=\mathrm{SR} \mathrm{R}^{\prime}\right)$ are suitable for the polymerization of conjugated monomers, while xanthates $(Z=$ $\left.O R^{\prime}\right)$ and dithiocarbamates $\left(Z=N R^{\prime}{ }_{2}\right)$ should be used for unconjugated monomers. ${ }^{2}, 3$ In addition, thiocarbonyl groups, especially dithioesters and trithiocarbonates, are sensitive to nucleophiles and decompose rapidly by, for example, amines. ${ }^{4}$

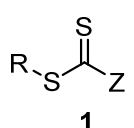

Figure 1. The general structure of RAFT CTAs.

The RAFT polymerization of acrylamides in polar solvents, such as alcohol and water, also requires careful selection of the RAFT agents. For example, when dithioester-based RAFT CTAs were used, a significant decrease in the control of both $M_{n}$ and dispersity was observed. ${ }^{5,6}$ McCormick reported the importance of acidic conditions for realizing the controlled polymerization of acrylamides in an aqueous solution. ${ }^{6-10}$ This finding is probably due to the degradation of RAFT CTAs without acid, but no experimental evidence for this hypothesis has been reported to date. Practically, trithiocarbonate-based CTAs, which are more tolerant to nucleophilic conditions than dithioester-based CTAs, have been utilized for the controlled polymerization of acrylamides, including

\footnotetext{
a. Institute for Chemical Research, Kyoto University, Uji 611-0011, Japan. E-mail:yamago@scl.kyoto-u.ac.jp

+Electronic Supplementary Information (ESI) available: [details of any supplementary information available should be included here]. See DOI: $10.1039 / \times 0 \times x 00000 x$
}

rare-earth metal triflate (RMT)-catalyzed stereoselective polymerization. ${ }^{11-18}$

In line with our interest in dual control over stereoregularity and molecular weight in the polymerization of acrylamides, ${ }^{19,}{ }^{20}$ we found that dithiobenzoate RAFT CTA $2 a(Z=P h)$ exhibits unique behavior; the control of molecular weight and dispersity, as well as that of tacticity, increased upon addition of RMT (Figure 2a). These results were in sharp contrast to those of trithiocarbonate $\mathbf{2 b}(\mathrm{Z}=$ $\mathrm{SMe})$, which resulted in a decrease in the molecular weight and dispersity control upon addition of RMT, while the tacticity control increased, as previously reported. ${ }^{11}, 12$ Control experiments revealed that RMT prevented the undesired side reaction of degradation of the dithioester group of $\mathbf{2 a}$. The detailed degradation mechanism of $2 a$ and the generality of RMT in the control are reported here.

\section{Results and discussion}

Polymerization of $\mathrm{N}, \mathrm{N}$-diethylacrylamide (DEAA, $\mathrm{R}^{\prime \prime}=$ $\mathrm{CONEt}_{2}, 100$ equiv.) in methanol was carried out using $\mathbf{2 a}$ and AIBN ( 0.25 equiv.) at $60^{\circ} \mathrm{C}$ in the absence of RMT (Table 1 , run 1). The monomer conversion was slow and reached $76 \%$ after $16 \mathrm{~h}$. The structure of the resulting PDEAA was not well controlled, as indicated by the deviation of the number average molecular weight determined by ${ }^{1} \mathrm{H}$ NMR $\left(M_{\mathrm{n}(\mathrm{NMR})}=\right.$ $12,700)$ from the theoretical value $\left(M_{\mathrm{n} \text { (theo) }}=9,900\right)$ and the broad dispersity $(\theta=1.56)$ determined by size exclusion chromatography (SEC) (Figure $2 b$, solid blue line). While the $M_{\mathrm{n}}$ determined by SEC $\left(M_{\mathrm{n}(\mathrm{SEC})}=9,400\right)$ was similar to $M_{\mathrm{n}(\text { theo }) \text {, }}$ we will use $M_{\mathrm{n}(\mathrm{NMR})}$ here because $M_{\mathrm{n}(\mathrm{SEC})}$ depends highly on the tacticity. ${ }^{19} \mathrm{~A}$ chain extension reaction by the addition of DEAA (500 equiv.) to the reaction mixture suggested the presence of $15 \%$ dead polymer in the initially formed PDEAA (Figure $2 \mathrm{~b}$, blue dotted line). The results indicate that degradation of the dormant end competes with polymerization. The characteristic red fading of the dithioester group was also consistent with degradation. 
a)

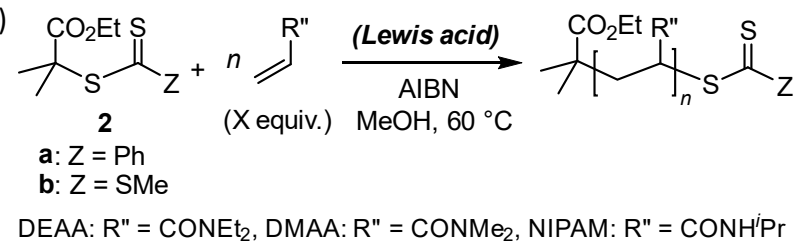

b)

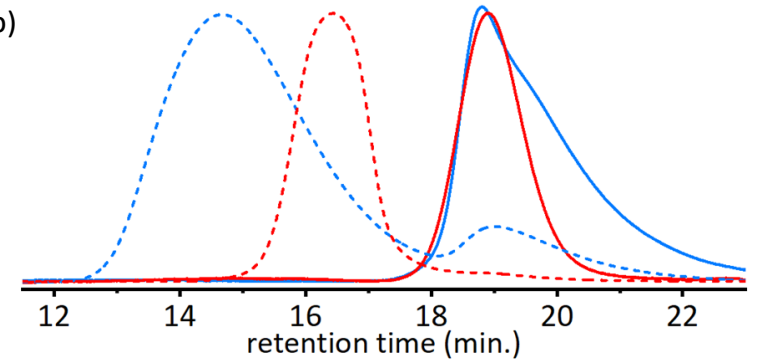

Figure 2. (a) RAFT polymerization of acrylamides using CTA 2a or $\mathbf{2 b}$ and (b) SEC traces before (solid line) and after (dotted line) the chain extension reaction (blue: run 1 , red: run 3 ).

Next, the same polymerization was conducted in benzene. The monomer conversion reached $88 \%$ after $8 \mathrm{~h}$, and structurally controlled PDEAA with a $M_{\mathrm{n} \text { (NMR) }}$ of $12,100\left(M_{\mathrm{n} \text { (theo) }}\right.$ $=11,500$ ) and dispersity of $\bigoplus=1.10$ was obtained (run 2). The red color was maintained during the polymerization. The results demonstrate the negative effect of methanol on decreasing the control. As the meso diad selectivity of the obtained PDEAA (60\%) was essentially the same as that obtained in methanol (58\%), the slow polymerization in methanol was probably caused by inhibition by the decomposed product(s) derived from $\mathbf{2 a}$.

Surprisingly, good control of the $M_{\mathrm{n}}$ and dispersity in methanol was observed upon the addition of $\mathrm{Y}(\mathrm{OTf})_{3}(0.10$ equiv. to DEAA). The monomer conversion reached $93 \%$ after $5 \mathrm{~h}$ (run 3), and structurally well-controlled PDEAA with $M_{\mathrm{n} \text { (NMR) }}=12,100\left(M_{\mathrm{n} \text { (theo) }}=12,100\right)$ and $\Theta=1.10$ was obtained. The meso diad selectivity also increased to $91 \%$, and the increase in the polymerization rate and stereoselectivity was consistent with previous reports. ${ }^{11,} 19,21$ A chain extension reaction using DEAA (500 equiv.) revealed nearly complete end-group fidelity ( $>98 \%$, Figure $2 b$, red lines). The results indicate that $\mathrm{Y}(\mathrm{OTf})_{3}$ blocks the degradation of the dithioester dormant end-group.

The amount of $\mathrm{Y}(\mathrm{OTf})_{3}$ could be reduced to 5.0 equivalents and further to 1.0 equivalents to obtain PDEAA with controlled $M_{\mathrm{n}}$ and low dispersity (runs 4 and 5). While the monomer conversion became slower and the meso diad selectivity decreased compared to that using 10 equivalents of $Y(O T f)_{3}$, the excellent control of $M_{n}$ and dispersity was preserved.

The stability of $\mathbf{2} \mathbf{a}$ in methanol was next examined. While $\mathbf{2 a}$ was reasonably stable, with only $9 \%$ degradation after $21 \mathrm{~h}$ at $60{ }^{\circ} \mathrm{C}$, in methanol, the addition of DEAA (10 equiv.) induced degradation. After $20 \mathrm{~h}$ of heating at $60^{\circ} \mathrm{C}, 86 \%$ of $2 \mathrm{a}$ was decomposed, and $O$ methyl benzothioate (3) and thioethers $\mathbf{4 c}$ and $\mathbf{4 d}$ with ethyl and methyl ester groups as $\mathrm{R}$ groups were formed in 93,66 , and $19 \%$ yields, respectively (Figure 3a). In contrast, the same experiment in the presence of $\mathrm{Y}(\mathrm{OTf})_{3}$ (1.0 equiv. to DEAA) nearly completely blocked the degradation of $2 \mathrm{a}(<2 \%)$ after $18 \mathrm{~h}$.

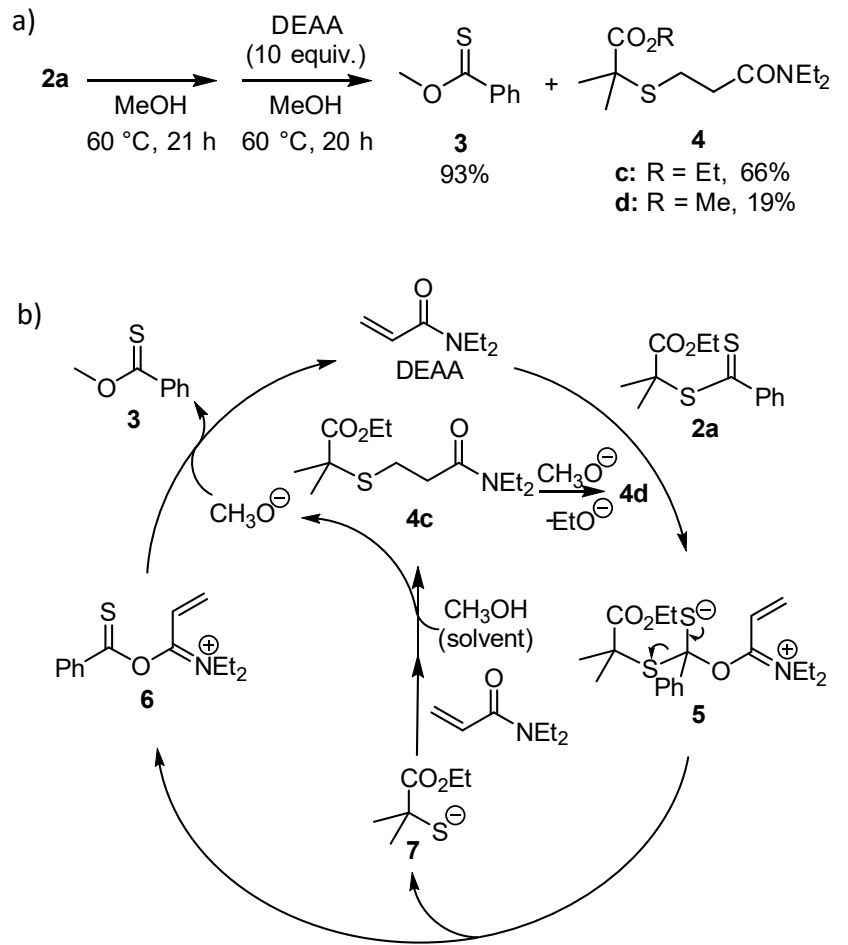

Figure 3. (a) Degradation of $\mathbf{2 a}$ in methanol in the presence of DEAA and (b) a possible degradation mechanism.

A plausible mechanism for the formation of $\mathbf{3}$ and $\mathbf{4}$ is shown in Figure $3 \mathrm{~b}$. Nucleophilic addition of the amide group of DEAA to $\mathbf{2 a}$ affords zwitterionic intermediate $\mathbf{5}$, from which elimination of thiolate $\mathbf{7}$ gives $\mathbf{6}$. Thiolate $\mathbf{7}$ adds to DEAA, and subsequent deprotonation by methanol affords $\mathbf{4 c}$ and methoxide ions, which react with 6 to yield 3 with the regeneration of DEAA. The methoxide also undergoes an ester exchange reaction with $\mathbf{4 c}$, affording $\mathbf{4 d}$. As $\mathrm{Y}(\mathrm{OTf})_{3}$ is a Lewis acid, its role is most likely to decrease the nucleophilicity of DEAA towards $\mathbf{2} \mathbf{a}$ by coordinating to DEAA.

The observed effect of $\mathrm{Y}(\mathrm{OTf})_{3}$ on the polymerization control using $2 \mathrm{a}$ was in sharp contrast to that using trithiocarbonate CTA 2b. The $M_{\mathrm{n}}$ and dispersity were well controlled in the absence of Lewis acids (run 6). However, the dispersity control decreased upon addition of $\mathrm{Y}(\mathrm{OTf})_{3}$ (run 7). A chain extension experiment demonstrated that loss of dispersity control was due to an increase in the polymerization rate instead of the degradation of the dormant chain ends. ${ }^{22}$ The different behaviors of $\mathbf{2 a}$ and $\mathbf{2} \mathbf{b}$ was probably due to the difference in the Lewis acid-base interactions between the dormant end species and $\mathrm{Y}(\mathrm{OTf})_{3}$, but further studies are needed to clarify this point. 
Table 1. RAFT polymerization of acrylamides in the presence of different Lewis acids. ${ }^{a}$

\begin{tabular}{|c|c|c|c|c|c|c|c|c|c|c|c|}
\hline run & $\begin{array}{l}\text { monomer } \\
\text { (equiv.) }\end{array}$ & CTA & $\begin{array}{l}\text { Lewis acid } \\
\text { (equiv.) }\end{array}$ & time (h) & $\begin{array}{l}\text { conv. } \\
(\%)^{b}\end{array}$ & $t_{1 / 2}(\mathrm{~h})^{c}$ & $\begin{array}{c}M_{\mathrm{n}(\mathrm{SEC})^{d}} \\
\times 10^{-3}\end{array}$ & $\begin{array}{c}M_{\mathrm{n}(\mathrm{NMR})}{ }^{e} \\
\times 10^{-3}\end{array}$ & $\begin{array}{c}M_{\mathrm{n} \text { (theo) }} \\
\times 10^{-3}\end{array}$ & $\bigoplus^{d}$ & $\begin{array}{c}m \\
(\%)^{e}\end{array}$ \\
\hline 1 & DEAA (100) & $2 a$ & none & 16 & 76 & 7.0 & 9.4 & 12.7 & 9.9 & 1.56 & 58 \\
\hline $2^{f}$ & DEAA (100) & $2 a$ & none & 8 & 88 & 3.1 & 9.3 & 12.1 & 11.5 & 1.10 & 60 \\
\hline 3 & DEAA (100) & $2 a$ & $\mathrm{Y}(\mathrm{OTf})_{3}(10)$ & 5 & 93 & 1.4 & 16.8 & 12.1 & 12.1 & 1.12 & 91 \\
\hline 4 & DEAA (100) & $2 a$ & $\mathrm{Y}(\mathrm{OTf})_{3}(5)$ & 9 & 92 & 2.7 & 15.4 & 12.8 & 12.0 & 1.15 & 85 \\
\hline 5 & DEAA (100) & $2 a$ & $\mathrm{Y}(\mathrm{OTf})_{3}(1)$ & 20 & 75 & 9.3 & 8.4 & 9.3 & 9.8 & 1.14 & 61 \\
\hline 6 & DEAA (100) & $2 b$ & none & 1.5 & 78 & 0.8 & 11.2 & 10.2 & 10.2 & 1.09 & 57 \\
\hline 7 & DEAA (100) & $2 b$ & $\mathrm{Y}(\mathrm{OTf})_{3}(10)$ & 1.5 & 98 & 0.4 & 15.3 & 12.7 & 12.7 & 1.30 & 90 \\
\hline 8 & DEAA (250) & $2 a$ & $\mathrm{Y}(\mathrm{OTf})_{3}(25)$ & 5 & 94 & 1.6 & 33.0 & 31.6 & 30.2 & 1.18 & 91 \\
\hline 9 & DEAA (500) & $2 a$ & $\mathrm{Y}(\mathrm{OTf})_{3}(50)$ & 8 & 94 & 2.6 & 59.3 & 55.5 & 60.0 & 1.24 & 91 \\
\hline 10 & DEAA (1000) & $2 a$ & $\mathrm{Y}(\mathrm{OTf})_{3}(100)$ & 10 & 92 & 2.9 & 95.3 & 127 & 117 & 1.34 & 90 \\
\hline 11 & DEAA (1500) & $2 a$ & $\mathrm{Y}(\mathrm{OTf})_{3}(150)$ & 10 & 90 & 3.7 & 126 & 168 & 172 & 1.47 & 90 \\
\hline 12 & DEAA (100) & $2 a$ & $\mathrm{Sc}(\mathrm{OTf})_{3}(10)$ & 8 & 77 & 4.0 & 8.4 & 9.1 & 10.1 & 1.15 & 72 \\
\hline 13 & DEAA (100) & $2 a$ & $\mathrm{La}(\mathrm{OTf})_{3}(10)$ & 5 & 98 & 1.4 & 17.4 & 13.2 & 12.7 & 1.13 & 90 \\
\hline 14 & DEAA (100) & $2 a$ & $\mathrm{Ce}(\mathrm{OTf})_{3}(10)$ & 4 & 89 & 1.7 & 15.9 & 12.1 & 11.6 & 1.13 & 90 \\
\hline 15 & DEAA (100) & $2 a$ & $\mathrm{Nd}(\mathrm{OTf})_{3}(10)$ & 4 & 92 & 1.5 & 16.5 & 12.4 & 12.0 & 1.16 & 90 \\
\hline 16 & DEAA (100) & $2 a$ & $\mathrm{Sm}(\mathrm{OTf})_{3}(10)$ & 4 & 93 & 1.4 & 17.6 & 12.7 & 12.1 & 1.16 & 91 \\
\hline 17 & DEAA (100) & $2 a$ & $\mathrm{Eu}(\mathrm{OTf})_{3}(10)$ & 17 & 78 & 8.1 & 10.6 & 10.0 & 10.2 & 1.19 & 90 \\
\hline 18 & DEAA (100) & $2 a$ & $\operatorname{Dy}(\mathrm{OTf})_{3}(10)$ & 4 & 91 & 1.6 & 15.1 & 12.2 & 11.8 & 1.12 & 89 \\
\hline 19 & DEAA (100) & $2 a$ & $\operatorname{Tm}(\mathrm{OTf})_{3}(10)$ & 5 & 93 & 1.8 & 18.4 & 13.1 & 12.1 & 1.11 & 89 \\
\hline 20 & DEAA (100) & $2 a$ & $\mathrm{Yb}(\mathrm{OTf})_{3}(10)$ & 5 & 90 & 1.7 & 14.7 & 11.7 & 11.7 & 1.15 & 91 \\
\hline 21 & DEAA (100) & $2 a$ & $\operatorname{Lu}(\mathrm{OTf})_{3}(10)$ & 5 & 96 & 1.4 & 17.5 & 12.4 & 12.5 & 1.14 & 89 \\
\hline 22 & DEAA (100) & $2 a$ & $\mathrm{YCl}_{3}(10)$ & 6 & 92 & 2.0 & 12.6 & 11.7 & 12.0 & 1.14 & 81 \\
\hline 23 & DEAA (100) & $2 a$ & $\mathrm{Y}\left(\mathrm{O}^{i} \mathrm{Pr}\right)_{3}(10)$ & 22 & 83 & 10 & 13.1 & 16.9 & 10.8 & 1.62 & 56 \\
\hline 24 & DMAA (100) & $2 a$ & none & 14 & 92 & 4.9 & 30.9 & 22.6 & 9.4 & 3.49 & 51 \\
\hline 25 & DMAA (100) & $2 a$ & $\mathrm{Y}(\mathrm{OTf})_{3}(10)$ & 4.5 & 87 & 1.4 & 17.5 & 9.9 & 8.9 & 1.14 & 84 \\
\hline 26 & NIPAM (100) & $2 a$ & none & 23 & 88 & 9.7 & 53.1 & 33.4 & 10.2 & 2.29 & 50 \\
\hline 27 & NIPAM (100) & $2 a$ & $\mathrm{Y}(\mathrm{OTf})_{3}(10)$ & 11 & 84 & 5.3 & 21.0 & 10.3 & 9.8 & 1.11 & 84 \\
\hline
\end{tabular}

a Polymerization was carried out by heating a solution of a monomer, CTA, and AIBN in methanol at $60{ }^{\circ} \mathrm{C}$, with $[\mathrm{Monomer}]_{0}=1.56$ mol L-1 (runs 1-23, 26 and 27) and $3.50 \mathrm{~mol} \mathrm{~L}^{-1}$ (runs 24 and 25). ${ }^{b}$ Determined by ${ }^{1} \mathrm{H}$ NMR in DMSO-d $d_{6}{ }^{c}$ See the Supporting Information. ${ }^{d}$ Determined by SEC using DMF containing $\mathrm{LiBr}\left(0.010 \mathrm{~mol} \mathrm{~L}^{-1}\right)$ as an eluent at $40{ }^{\circ} \mathrm{C}$ against poly(methyl methacrylate) (PMMA) standards. ${ }^{e}$ Determined by ${ }^{1} \mathrm{H}$ NMR in DMSO- $d_{6}$ at $130{ }^{\circ} \mathrm{C}$ (PDEAA, PDMAA) and $145{ }^{\circ} \mathrm{C}$ (PNIPAM). ${ }^{f}$ The polymerization was conducted in benzene.

The advantage of CTA $2 \mathrm{a}$ in the presence of $\mathrm{Y}(\mathrm{OTf})_{3}$ was demonstrated by the synthesis of high-molecular-weight PDEAAs with controlled $M_{n}$, dispersity, and tacticity (runs 811). When $250,500,1000$, and 1500 equivalents of DEAA were employed, corresponding PDEAAs with controlled $M_{\mathrm{n}}$ up to 168,000 and low dispersity $(\theta<1.5)$ with $\sim 90 \%$ meso diad selectivity were obtained. The results are in sharp contrast to those of previous work, in which the control of $M_{\mathrm{n}}$ and dispersity significantly decreased when the targeted $M_{\mathrm{n}}$ was increased. ${ }^{19}$ Therefore, the current result is among the best obtained for the dual control of molecular weight and tacticity. As $\mathbf{2} \mathbf{a}$ is also effective for the controlled polymerization of other acrylamides in the presence of $\mathrm{Y}(\mathrm{OTf})_{3}$ (see below), the method is suitable for synthesizing high-molecular-weight polyacrylamides $\left(M_{\mathrm{n}}>10,000\right)$ with controlled $M_{\mathrm{n}}$ and tacticity.

We found that RMTs are generally effective for preventing degradation of the thiocarbonyl group in the polymerization of DEAA in methanol; while we could not investigate all lanthanide triflates, all the lanthanide triflates we examined (metal center $=\mathrm{La}$, $\mathrm{Ce}, \mathrm{Nd}, \mathrm{Sm}, \mathrm{Eu}, \mathrm{Dy}, \mathrm{Tm}, \mathrm{Yb}$, and $\mathrm{Lu}$ ) and Sc(OTf $)_{3}$ afforded PDEAAs with controlled $M_{\mathrm{n}}$ and low dispersity using $2 \mathrm{a}(\Theta<1.20$, runs 12 21). As these RMTs were also effective for tacticity control, as previously reported, ${ }^{14}$ PDEAAs with more than $72 \%$ meso diad selectivity were formed in all cases. Furthermore, rate 
enhancement of the polymerization was also observed in all cases except for $\mathrm{Eu}(\mathrm{OTf})_{3}$.

We further examined the effect of Lewis acid species by changing the counteranion and the metal center. $\mathrm{YCl}_{3}$ was found to be effective for the control of $M_{n}$ and dispersity, with modest meso diad selectivity (run 22), but $Y\left(O^{\prime} P r\right)_{3}$ was inefficient for $M_{n}$, dispersity, and tacticity control (run 23). Metal triflates derived from alkali metals ( $\mathrm{M}=\mathrm{Li}, \mathrm{Na}, \mathrm{K}$ ) and alkaline earth metals $(\mathrm{M}=\mathrm{Mg}$, Ca) were generally ineffective, and the dispersity of the resulting PDEAAs was broad $(\theta>2$, see the Supporting Information). Notably, these metal triflates did not affect the tacticity or monomer conversion rate. Furthermore, the red fading of the RAFT agents suggested the degradation of the dormant species. No clear trend was observed for the transition metal $(\mathrm{M}=\mathrm{Zn}$, and $\mathrm{Cu}$ )-derived metal triflates; the dispersity control slightly increased with $\mathrm{Zn}(\mathrm{OTf})_{2}$, but $\mathrm{Cu}(\mathrm{OTf})_{2}$ completely inhibited the polymerization.

The relation among dispersity control, meso diad selectivity, and the rate of monomer conversion was plotted (Figure 4). As the polymerization rate did not follow first-order kinetics, the half-life $\left(t_{1 / 2}\right)$ of monomer conversion was used instead of the rate constant. RMTs and $\mathrm{YCl}_{3}$ are generally effective for dispersity control by preventing the degradation of $\mathbf{2 a}$. Interestingly, these Lewis acids were also effective for tacticity control; when $10 \mathrm{~mol} \%$ of these Lewis acids relative to the DEAA content were used, $>70 \%$ meso diad selectivity was observed. Additionally, these Lewis acids were effective in increasing the polymerization rate besides $\mathrm{Eu}(\mathrm{OTf})_{3}$. However, an increase in the meso diad selectivity or polymerization rate is not necessary to prevent the degradation of $\mathbf{2 a}$, as exemplified in the polymerization using 1.0 equivalent of $\mathrm{Y}(\mathrm{OTf})_{3}$. These results suggest the importance of the interaction between acrylamides and rare-earth metal-based Lewis acids. As RMT-based Lewis acids are well known to have high oxophilicity, ${ }^{23-}$ 25 this character may play a role here. Further studies are needed to clarify this point.

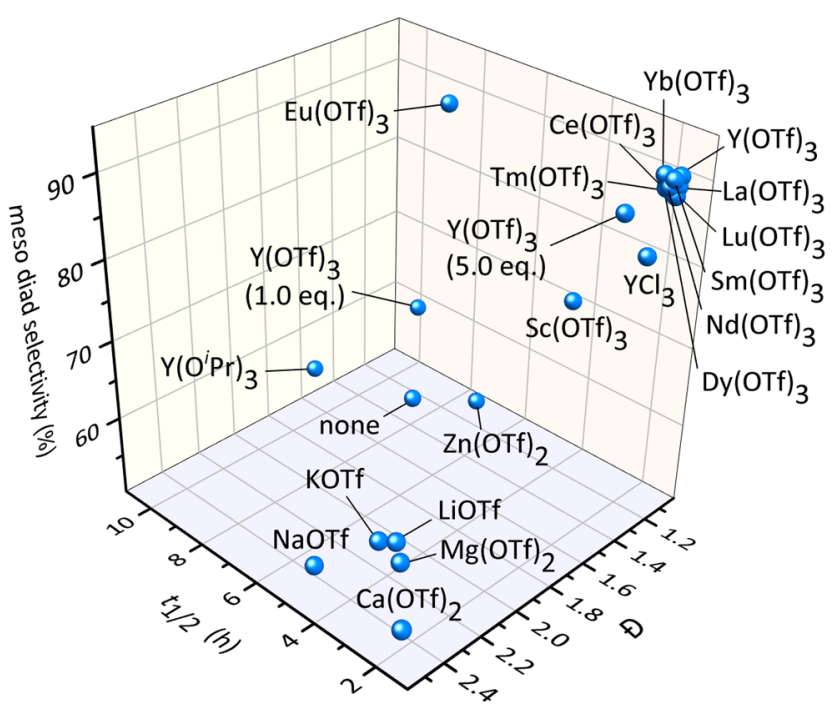

Figure 4. The effect of dispersity $(\Theta)$ on the meso diad selectivity (\%) and polymerization rate $\left[t_{1 / 2}(\mathrm{~h})\right]$ in the polymerization of DEAA (100 equiv.) using $\mathbf{2 a}$ in the presence of Lewis acids. Except as shown in the parentheses, 10 equivalents of Lewis acids were used.

Finally, the generality of the effect of RMTs was investigated using $\mathrm{N}, \mathrm{N}$-dimethylacrylamide (DMAA, R" = $\mathrm{CONMe}_{2}$ ) and $\mathrm{N}$-isopropylacrylamide (NIPAM, R" = CONH ${ }^{i} \mathrm{Pr}$ ) as monomers. In both cases, the control of $M_{n}$ and dispersity could not be achieved in the absence of Lewis acids, but excellent control was observed upon addition of $\mathrm{Y}(\mathrm{OTf})_{3}$ (runs 24-27, Figure 5).
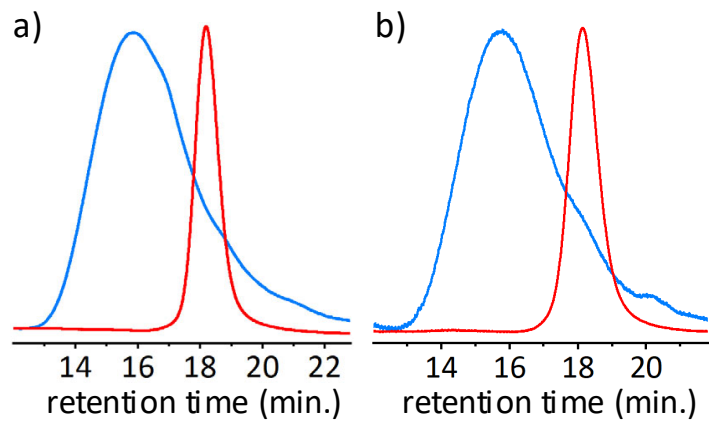

Figure 5. SEC traces of (a) PDMAA and (b) PNIPAM samples synthesized in the absence (blue) or presence (red) of $\mathrm{Y}(\mathrm{OTf})_{3}$.

\section{Conclusion}

The degradation mechanism of the dithioester end-group in the RAFT polymerization of acrylamides in methanol was clarified. In addition, RMT blocks the degradation and increases stereoselectivity, affording polyacrylamides with controlled molecular weight and tacticity. The level of control achieved under the current conditions is among the best for dual control reported to date. These new findings are expected to expand the utility of RAFT polymerization for the synthesis of advanced polymeric molecules based on polyacrylamides.

\section{Experimental}

\section{Materials}

Unless otherwise noted, chemicals obtained from commercial suppliers were used as received. DEAA and DMAA were dried over $\mathrm{CaH}_{2}$, distilled under reduced pressure, deaerated by passing nitrogen gas for $>0.5 \mathrm{~h}$, and stored under nitrogen. NIPAM was recrystallized from hexane and stored under nitrogen. Lewis acids were dried under reduced pressure at $100{ }^{\circ} \mathrm{C}$ (for $>4 \mathrm{~h}$ ). AIBN was recrystallized from methanol and stored in a refrigerator. Methanol was distilled over Mg turnings, deaerated by passing nitrogen gas, and stored over molecular sieve $3 \mathrm{~A}$ under nitrogen. $\alpha, \alpha, \alpha-$ Trifluorotoluene was distilled, deaerated by passing nitrogen gas, and stored under nitrogen. 2a was synthesized as reported. ${ }^{26}$ Synthesis of $\mathbf{2} \mathbf{b}$ is described in the Supporting Information.

\section{Characterization}


${ }^{1} \mathrm{H}$ NMR $(400 \mathrm{MHz})$ spectra were obtained for DMSO- $d_{6}$ or $\mathrm{CDCl}_{3}$ solutions of the samples and are reported in ppm ( $\delta$ ) relative to a solvent peak or internal standard (tetramethylsilane). The ${ }^{13} \mathrm{C}$ NMR $(100 \mathrm{MHz})$ spectrum was measured for the $\mathrm{CDCl}_{3}$ solution of a sample and is reported in ppm $(\delta)$ relative to a solvent peak $\left(\mathrm{CHCl}_{3}\right)$. SEC was performed on a machine equipped with two linearly connected polystyrene mixed gel columns (Shodex LF-604) at $40{ }^{\circ} \mathrm{C}$ using refractive index (RI) detectors. DMF containing $\mathrm{LiBr}(0.010$ $\left.\mathrm{mol} \cdot \mathrm{L}^{-1}\right)$ was used as an eluent at a flow rate of $1.0 \mathrm{~mL} \cdot \mathrm{min}^{-1}$. Molecular weights were calibrated against PMMA standards. Preparative SEC was performed on linearly connected JAIGEL $1 \mathrm{H}$ and $2 \mathrm{H}(\times 2)$ polystyrene columns (Japan Analytical Industry Co., Ltd.) with $\mathrm{CHCl}_{3}$ as an eluent or JAIGEL $1 \mathrm{HH}$ and $2 \mathrm{HH}$ polystyrene columns with THF as an eluent. High-resolution mass spectra (HRMS) were obtained under atmospheric pressure chemical ionization (APCI) or electron ionization (EI) conditions.

Degradation of $2 \mathrm{a}$ in methanol. A solution of $2 \mathrm{a}(1.8 \mathrm{~mL}$, $0.97 \mathrm{~mol} \mathrm{~L}^{-1}$ in methanol, $1.75 \mathrm{mmol}$ ) and $\alpha, \alpha, \alpha-$ trifluorotoluene (107 $\mu \mathrm{L}, 0.88 \mathrm{mmol}$, an internal standard) in methanol $(17.5 \mathrm{~mL})$ was heated at $60{ }^{\circ} \mathrm{C}$ under a nitrogen atmosphere, and the consumption of $\mathbf{2 a}$ was periodically monitored by withdrawing an aliquot for ${ }^{1} \mathrm{H}$ NMR analysis. The conversion of $2 \mathrm{a}$ was $9 \%$ after $21 \mathrm{~h}$. DEAA ( $2.39 \mathrm{~mL}, 17.5 \mathrm{mmol})$ was added, and the resulting mixture was heated at $60^{\circ} \mathrm{C}$. The consumption of $\mathbf{2 a}$ reached $95 \%$ after $20 \mathrm{~h}$. Formation of 3, 4c and $\mathbf{4 d}$ in $93 \%, 66 \%$, and $19 \%$ yields, respectively, was confirmed by ${ }^{1} \mathrm{H}$ NMR analysis. The solvent was removed under reduced pressure, and the crude mixture was separated by silica gel column chromatography (eluted with hexane, followed by ethyl acetate), affording 3 (166 mg) in 62\% yield. The remaining mixture was purified by preparative SEC (eluent: $\mathrm{CHCl}_{3}$ ), affording a mixture of $\mathbf{4 c}$ and $4 \mathrm{~d}$ (109 mg, $82: 18$ ) in 19 and $4 \%$ yields, respectively.

3: IR (neat): 1652, 1541, 1315, 1273, 1229; HRMS (APCI) $\mathrm{m} / \mathrm{z}$ : Calcd for $\mathrm{C}_{8} \mathrm{H}_{9} \mathrm{OS}(\mathrm{M}+\mathrm{H})^{+}, 153.0369$; Found $153.0367,{ }^{1} \mathrm{H}$ NMR $\left(400 \mathrm{MHz}, \mathrm{CDCl}_{3}\right) 4.31\left(\mathrm{~s},-\mathrm{OCH}_{3}\right), 7.36-7.43(\mathrm{~m}, 2 \mathrm{H}, \mathrm{ArH})$, 7.50-7.57 (m, $1 \mathrm{H}, \mathrm{ArH}), 8.16-8.22(\mathrm{~m}, 2 \mathrm{H}, \mathrm{ArH}) ;{ }^{13} \mathrm{C}$ NMR (100 $\mathrm{MHz}, \mathrm{CDCl}_{3}$ ): 59.43, 128.22, 128.90, 132.85, 138.41, 212.47.

4c and 4d (an 82:18 mixture): IR (neat): 1719, 1653, 1560, 1460, 1265; HRMS (EI) $\mathrm{m} / \mathrm{z}$ : Calcd for $\mathrm{C}_{13} \mathrm{H}_{25} \mathrm{NO}_{3} \mathrm{~S}$ (4c) (M)+, 275.1555; Found 275.1559, Calcd for $\mathrm{C}_{12} \mathrm{H}_{23} \mathrm{NO}_{3} \mathrm{~S}$ (4d) (M)+, 261.1399; Found 261.1402; ${ }^{1} \mathrm{H} \mathrm{NMR}\left(400 \mathrm{MHz}, \mathrm{CDCl}_{3}\right) 1.11$ (t, $\left.J=7.1 \mathrm{~Hz}, 3 \mathrm{H},-\mathrm{N}\left(\mathrm{CH}_{2} \mathrm{CH}_{3}\right)_{2}\right), 1.16\left(\mathrm{t}, J=7.1 \mathrm{~Hz}, 3 \mathrm{H},-\mathrm{N}\left(\mathrm{CH}_{2} \mathrm{CH}_{3}\right)_{2}\right)$, $1.29\left(\mathrm{t}, J=7.1 \mathrm{~Hz}, 3 \mathrm{H}\right.$ for $\left.4 \mathrm{c},-\mathrm{CO}_{2} \mathrm{CH}_{2} \mathrm{CH}_{3}\right), 1.52(\mathrm{~s}, 6 \mathrm{H}$ for $4 \mathrm{c}$, $\left.\mathrm{C}\left(\mathrm{CO}_{2} \mathrm{Et}\right)\left(\mathrm{CH}_{3}\right)_{2}\right), 1.53$ (s, $6 \mathrm{H}$ for $\left.4 \mathrm{~d},-\mathrm{C}\left(\mathrm{CO}_{2} \mathrm{CH}_{3}\right)\left(\mathrm{CH}_{3}\right)_{2}\right), 2.529$ (t, $J=7.8,7.6 \mathrm{~Hz}, 2 \mathrm{H}$ for $\left.4 \mathrm{~d},-\mathrm{CH}_{2} \mathrm{CH}_{2} \mathrm{CONEt}_{2}\right), 2.534(\mathrm{t}, J=7.8,7.6$ $\mathrm{Hz}, 2 \mathrm{H}$ for $\left.4 \mathrm{c},-\mathrm{CH}_{2} \mathrm{CH}_{2} \mathrm{CONEt}_{2}\right), 2.93(\mathrm{t}, J=7.8,7.6 \mathrm{~Hz}, 2 \mathrm{H}$ for 4d, $\left.-\mathrm{CH}_{2} \mathrm{CH}_{2} \mathrm{CONEt}_{2}\right), 2.94(\mathrm{t}, J=7.8,7.6 \mathrm{~Hz}, 2 \mathrm{H}$ for $4 \mathrm{c}$, $\mathrm{CH}_{2} \mathrm{CH}_{2} \mathrm{CONEt}_{2}$ ), 3.28 (q, J= 7.1, 7.3 Hz, $\left.2 \mathrm{H},-\mathrm{N}\left(\mathrm{CH}_{2} \mathrm{CH}_{3}\right)_{2}\right), 3.37$ (q, $\left.J=7.1,7.3 \mathrm{~Hz}, 2 \mathrm{H},-\mathrm{N}\left(\mathrm{CH}_{2} \mathrm{CH}_{3}\right)_{2}\right), 3.73\left(\mathrm{~s}, 3 \mathrm{H}\right.$ for $\left.4 \mathrm{~d},-\mathrm{CO}_{2} \mathrm{CH}_{3}\right)$, 4.18 (q, $J=7.1,7.3 \mathrm{~Hz}, 2 \mathrm{H}$ for $\left.4 \mathrm{c},-\mathrm{CO}_{2} \mathrm{CH}_{2} \mathrm{CH}_{3}\right) ;{ }^{13} \mathrm{C}$ NMR (100
$\mathrm{MHz}, \mathrm{CDCl}_{3}$ ) 4c: $13.23,14.30,14.43,25.47,25.93,33.32,40.39$, 42.00, 47.28, 61.36, 170.13, 174.47 (Four peaks at 25.50, 25.95, 33.23 and $52.56 \mathrm{ppm}$ are derived from $\mathbf{4 d}$. Other peaks of $\mathbf{4 d}$ could not be identified possibly due to the overrapping with the peaks of $\mathbf{4 c}$.)

Typical experimental procedure. RAFT polymerization of DEAA using $\mathrm{Y}(\mathrm{OTf})_{3}$ A solution of $2 \mathrm{a}(6.3 \mu \mathrm{l}, 0.025 \mathrm{mmol})$, DEAA ( $342 \mu \mathrm{l}, 2.5 \mathrm{mmol}$ ), AIBN ( $30 \mu \mathrm{l}, 0.20 \mathrm{~mol} \mathrm{~L}^{-1}$ in methanol, $0.0063 \mathrm{mmol}$ ), $\alpha, \alpha, \alpha$-trifluorotoluene ( $31 \mu \mathrm{l}, 0.25 \mathrm{mmol}$, an internal standard), and $\mathrm{Y}(\mathrm{OTf})_{3}(134 \mathrm{mg}, 0.25 \mathrm{mmol})$ in methanol $(1.6 \mathrm{~mL})$ was heated at $60{ }^{\circ} \mathrm{C}$ under a nitrogen atmosphere. The progress of the polymerization was monitored by withdrawing aliquots for ${ }^{1} \mathrm{H}$ NMR analysis. The monomer conversion reached $93 \%$ after $5 \mathrm{~h}$. The SEC analysis determined a $M_{\mathrm{n}}$ of 16,800 and a $\emptyset$ of $1.12 .{ }^{1} \mathrm{H}$ NMR analysis (DMSO- $d_{6}, 130^{\circ} \mathrm{C}$ ) determined a meso diad selectivity $(91 \% \mathrm{~m}$ ).

A chain extension experiment was carried out by adding DEAA $(1.71 \mathrm{ml}, 12.5 \mathrm{mmol})$ and AIBN $\left(30 \mu \mathrm{l}, 0.20 \mathrm{~mol} \mathrm{~L}^{-1}\right.$ in methanol, $0.0063 \mathrm{mmol}$ ) and heating the sample for $4 \mathrm{~h}$. The conversion of the added DEAA reached $89 \%$. The SEC analysis determined a $M_{\mathrm{n}}$ of 76,700 and a $\Theta$ of 1.27. The end-group fidelity was estimated to be $>98 \%$, as analyzed by the peak separation method.

Typical experimental procedure. RAFT polymerization of DEAA with higher molecular weight using $Y(O T f)_{3}$. A solution of $2 \mathrm{a}\left(1.0 \mu \mathrm{l}, 1.49 \mathrm{~mol} \mathrm{~L}^{-1}\right.$ in methanol, $\left.0.0015 \mathrm{mmol}\right)$, DEAA (308 $\mu \mathrm{l}, 2.25 \mathrm{mmol})$, AIBN $\left(4.8 \mu \mathrm{l}, 0.078 \mathrm{~mol} \mathrm{~L}^{-1}\right.$ in methanol, $0.00038 \mathrm{mmol}), \alpha, \alpha, \alpha$-trifluorotoluene $(28 \mu \mathrm{l}, 0.23 \mathrm{mmol}$ as an internal standard), and $\mathrm{Y}(\mathrm{OTf})_{3}(121 \mathrm{mg}, 0.23 \mathrm{mmol})$ in methanol $(1.4 \mathrm{~mL})$ was heated at $60{ }^{\circ} \mathrm{C}$. The monomer conversion reached $90 \%$ after $10 \mathrm{~h}$. The crude mixture was diluted with $2 \mathrm{~mL}$ of methanol, and part of the solution was poured into vigorously stirred diethyl ether $(250 \mathrm{~mL})$. The product collected by suction filtration was dried under reduced pressure at $100{ }^{\circ} \mathrm{C}$ overnight (229 mg). The SEC analysis determined a $M_{n}$ of 125,700 and a $€$ of 1.47 . Note that the sample for the SEC analysis had to be prepared in methanol. When the sample was prepared in DMF, a broad new signal in the high-molecular-weight region was observed, probably because of the low solubility of PDEAA with high meso diad selectivity in DMF due to the increase in crystallinity. ${ }^{27}{ }^{1} \mathrm{H}$ NMR (DMSO- $d_{6}, 130^{\circ} \mathrm{C}$ ) analysis was used to determine the meso diad selectivity $(90 \% \mathrm{~m})$.

\section{Conflicts of interest}

There are no conflicts to declare.

\section{Acknowledgments}


This work was partly supported by the Japan Society for the Promotion of Science (JSPS) KAKENHI Grant No. $21 \mathrm{H} 04693$ (S.Y.).

\section{Notes and references}

1 G. Moad, E. Rizzardo, S. H. Thang, Polymer, 2008, 49, 10791131.

2 S. Perrier, P. Takolpuckdee, J. Polym. Sci., Part A: Polym. Chem., 2005, 43, 5347-5393.

3 G. Moad, E. Rizzardo, S. H. Thang, Aust. J. Chem., 2012, 65, 985-1076.

4 G. Moad, E. Rizzardo, S. H. Thang, Polym. Int., 2011, 60, 9-25.

5 B. Ray, Y. Isobe, K. Morioka, S. Habaue, Y. Okamoto, M. Kamigaito, M. Sawamoto, Macromolecules, 2003, 36, 543545.

6 D. B. Thomas, B. S. Sumerlin, A. B. Lowe, C. L. McCormick, Macromolecules, 2003, 36, 1436-1439.

7 M. S. Donovan, T. A. Sanford, A. B. Lowe, B. S. Sumerlin, Y. Mitsukami, C. L. McCormick, Macromolecules, 2002, 35, 4570-4572.

8 M. S. Donovan, B. S. Sumerlin, A. B. Lowe, C. L. McCormick, Macromolecules, 2002, 35, 8663-8666.

9 Y. Li, B. S. Lokitz, C. L. McCormick, Angew. Chem. Int. Ed., 2006, 45, 5792-5795.

10 B. S. Lokitz, A. J. Convertine, R. G. Ezell, A. Heidenreich, Y. Li, C. L. McCormick, Macromolecules, 2006, 39, 8594-8602.

11 S. Shanmugam, C. Boyer, J. Am. Chem. Soc., 2015, 137, 99889999.

12 M. Nuopponen, K. Kalliomäki, A. Laukkanen, S. Hietala, H. Tenhu, J. Polym. Sci., Part A: Polym. Chem., 2008, 46, 38-46.

13 X. Su, Z. Zhao, H. Li, X. Li, P. Wu, Z. Han, Eur. Polym. J., 2008, $44,1849-1856$.

14 Y. Isobe, D. Fujioka, S. Habaue, Y. Okamoto, J. Am. Chem. Soc., 2001, 123, 7180-7181.

15 Y. Isobe, T. Nakano, Y. Okamoto, J. Polym. Sci., Part A: Polym. Chem., 2001, 39, 1463-1471.

16 Y. Suito, Y. Isobe, S. Habaue, Y. Okamoto, J. Polym. Sci., Part A: Polym. Chem., 2002, 40, 2496-2500.

17 Y. Okamoto, S. Habaue, Y. Isobe, in Advances in Controlled/Living Radical Polymerization, American Chemical Society, 2003, Vol. 854, Chap. 5, pp. 59-71.

18 Y. Isobe, Y. Suito, S. Habaue, Y. Okamoto, J. Polym. Sci., Part A: Polym. Chem., 2003, 41, 1027-1033.

19 Y. Imamura, T. Fujita, Y. Kobayashi, S. Yamago, Polym. Chem., 2020, 11, 7042-7049.

20 B. Park, Y. Imamura, S. Yamago, Polym. J., 2020, 53, 515-521.

21 J.-F. Lutz, D. Neugebauer, K. Matyjaszewski, J. Am. Chem. Soc., 2003, 125, 6986-6993.

22 A. Goto, T. Fukuda, Prog. Polym. Sci., 2004, 29, 329-385.

23 H. C. Aspinall, Chem. Rev., 2002, 102, 1807-1850.

24 M. Shibasaki, N. Yoshikawa, Chem. Rev., 2002, 102, 21872210.

25 S. Kobayashi, M. Sugiura, H. Kitagawa, W. W.-L. Lam, Chem. Rev., 2002, 102, 2227-2302.

26 Y. Kwak, R. Nicolaÿ, K. Matyjaszewski, Macromolecules, 2009, 42, 3738-3742.

27 B. Park, M. Tosaka, S. Yamago, Polym. J., 2021, 53, 533-538. 